\title{
O PIBID NO CURSO DE PEDAGOGIA: DESAFIOS E POSSIBILIDADES FORMATIVAS ${ }^{1}$
}

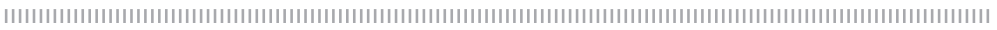

\author{
Maria Lucia Marocco Maraschin ${ }^{2}$ \\ Vanda Mari Trombetta ${ }^{3}$
}

\begin{abstract}
RESUMO
Trata-se de exercício analítico que reflete a construção e a implementação da proposta pedagógica do Programa Institucional de Bolsas de Iniciação à Docência (PIBID) Subprojeto Pedagogia na interface com os compromissos ético formativos da instituição, do curso e as aproximações iniciais com o campo de atuação profissional: a escola. O objetivo principal é socializar as incursões efetuadas até então, priorizando a formação e a aproximação inicial dos estudantes do e com o processo formativo em curso, dadas as especificidades do ingresso dos estudantes nas fases iniciais do curso de pedagogia. Metodologicamente trata-se de
\end{abstract}

\footnotetext{
${ }^{1}$ Artigo inerente aos compromissos ético políticos do Programa Institucional da Universidade Federal da Fronteira Sul (UFFS) e do Subprojeto Pedagogia da mesma instituição. Campi Laranjeiras do Sul/PR e Chapecó/SC.

2 Doutora em Educação. Professora adjunta da Universidade Federal da Fronteira Sul (UFFS), coordenadora de área do Subprojeto de Pedagogia (Campus Chapecó/SC) do PIBID-UFFS. Contato: maria.maraschin@uffs.edu.br

3 Doutora em letras. Professora adjunta da Universidade Federal da Fronteira Sul (UFFS), coordenadora de área do Subprojeto de Pedagogia (Campus Laranjeiras do Sul/PR) do PIBID-UFFS. Contato: vandamtt@uffs.edu.br
} 
um percurso formativo teórico prático, subsidiado, pela leitura de obras, artigos, relatos de experiências e de realidades vividas e materializadas nas unidades escolares na atualidade. Como resultados desse exercício, podemos afirmar que apreender a realidade da escola, sob a mediação de professores da universidade e da escola, constituiu-se num desafio para ambos, uma vez que a relação empática demanda respeito às singularidades e saberes típicos de cada espaço. Entre as particularidades a serem destacadas estão às concepções de alfabetização e letramento, subsidiadas pela Base Nacional Comum Curricular (BNCC) e pelos compromissos com a formação inicial e continuada expressa nas relações entre universidade escola, atentas ao contexto educacional vigente.

Palavras-chave: Percurso formativo. Formação inicial para a Docência. Relação escola-universidade.

\section{ASPECTOS CONCEITUAIS E OS VÍNCULOS DO PROGRAMA INSTITUCIONAL DE BOLSA DE INICIAÇÃO À DOCÊNCIA (PIBID) COM O CONTEXTO FORMATIVO INICIAL E CONTINUADO}

O processo de aproximação oportunizado pela formação inicial mediada pela participação universidade, escola e sujeito aprendente da docência requer disponibilidade, empatia e reconhecimento do saber do outro e dos espaços que esse ocupa nessa relação. Em razão disso, Tardif (2000) faz um apelo, de modo que, nessa relação universidade-escola, possamos compreender que os saberes se complementam e que as relações colaborativas e coletivas podem vir a possibilitar relações ímpares para a formação inicial e continuada dos e para os profissionais da educação. Em razão disso reitera que:

[...] se os pesquisadores universitários querem estudar os saberes profissionais da área do ensino, devem sair de seus laboratórios, sair de seus gabinetes na universidade, 
largar seus computadores, largar seus livros e os livros escritos por seus colegas que definem a natureza do ensino, os grandes valores educativos ou as leis da aprendizagem, e ir diretamente aos lugares onde os profissionais do ensino trabalham, para ver como eles pensam e falam, como trabalham na sala de aula, como transformam programas escolares para torná-los efetivos, como interagem com os pais dos alunos, com seus colegas etc. (TARDIF, 2000, p.12, grifos nossos).

O Programa Institucional de Bolsa de Iniciação à Docência (PIBID) constituiu-se desde meados de 2007 em uma política pública que tem fomentado a formação inicial de professores no Brasil. Proposto e viabilizado com apoio da Coordenação de Aperfeiçoamento de Pessoal de Nível Superior (Capes), esse Programa vem objetivando, que os discentes em formação inicial conheçam e aproximem do e no espaço escolar e do seu cotidiano para vivenciar no que se constitui a docência, criando e participando de experiências teórico-metodológicas, no espaço escolar, em parceria com o(a) professor(a) e com a escola de Educação Básica.

O Programa vem desempenhando um papel primordial na formação docente, na medida em que "[...] proporciona ao graduando/bolsista a vivência da teoria na prática e a aplicação da prática dentro da teoria para, assim, poder perceber que a teoria não está distante da prática, como até então era pensado, enquanto não se vive essa realidade." (TEMÓTEO; SILVA, 2014, p. 115).

Os pesquisadores da Fundação Carlos Chagas (2014), ao analisarem a produção bibliográfica sobre o PIBID e os dados obtidos pela aplicação de questionários aos bolsistas envolvidos, fizeram alguns destaques interessantes. A exemplo, podemos observar a construção de um panorama, em nível nacional, das discussões e contribuições do PIBID para a formação docente. Ilustrando de modo mais especifico, os autores argumentam que a 
criação do Programa se constituiu numa medida estratégica para a solução dos problemas existentes nos cursos de licenciatura de nível superior, notadamente, no âmbito da relação teoria e prática e, ainda, pela possibilidade de inserir os graduandos no cotidiano da docência, podendo assim qualificá-la, criando adesão e permanência no curso de licenciatura.

Ao esboçar a grandiosidade do Programa, em termos de política pública para formação docente por sua abrangência a todas as licenciaturas e a outras configurações da docência, pesquisadores da Fundação Carlos Chagas (2014) e demais autores destacados na citação subsequente, assinalam o envolvimento de outros atores no Programa:

Um diferencial nesse Programa é a concessão de bolsas não só a estudantes das licenciaturas, mas também aos professores das universidades que os orientam, e a professores das escolas públicas (chamados supervisores) que acompanham as atividades dos bolsistas no espaço escolar, atuando assim como conformadores no processo de iniciação à docência, em articulação com o formador da universidade. (FUNDAÇÃO CARLOS CHAGAS,. 2014, p. 9-10).

Diante da dimensão, abrangência do PIBID, e de suas contribuições para a formação inicial de professores, aqui particularizada no Curso de Pedagogia, no sentido de contribuir para uma postura crítica, de reflexão sobre sua ação e sobre a realidade na qual esse profissional está inserido, e sobre as mudanças que ocorrem frequentemente na sociedade o que se busca é na relação teoria e prática, para por seu intermédio compreender as novas demandas da sociedade em relação à Educação Infantil, Anos Iniciais do Ensino Fundamental è̀ Gestão escolar, eixos basilares na formação do profissional da Pedagogia.

Vale destacar que a formação inicial dos professores aqui ensejada vem sendo subsidiada pelos olhares de Tardif (2004), 
Pimenta (2000) e Freire (2009), dentre outros que zelam e se ocupam da profissão e da profissionalidade docente. Há de acordo com os próprios autores pontos de convergência e reciprocidade evidenciando que a formação para a docência requer um olhar que se destine ao professor enquanto sujeito pessoa, constituído particular e coletivamente e um pensar sobre a ação prática com vistas à autonomia do mesmo enquanto ser humano e profissional.

Cabe-nos ainda reiterar que dentre as singularidades destacadas buscamos compreender a práxis educativa tendo em vistas atender às demandas da sociedade vigente, cuja proposta formativa norteia-se por algumas problematizações: o que há de novo no contexto do PIBID Pedagogia-UFFS? O que tem sido evidenciado e relatado nos diários de bordo tendo em vista a compreensão e a ressignificação desse processo formativo? Que influências em relação à constituição da profissionalidade docente e que finalidades cumprem as práticas pedagógicas acompanhadas no âmbito do PIBID Pedagogia-UFFS?

Essas problematizações transversalizam a proposta pedagógica do curso de formação em atenção a suas especificidades formativas, buscando aproximações sistemáticas com a escola, enquanto lócus, espaço de formação e atuação profissional, cujas influências redimensionam, qualificam e forjam mudanças, no âmbito do fazer e do fazer-se docente. Em razão disso, trazemos o Programa e suas especificidades como exercício formativo, mediado por um percurso colaborativo e coletivo, ancorado em compromissos ético/políticos que permeiam a relação universidade escola, professores da Educação Básica, professores da Educação Superior e estudantes da Educação Básica e da Educação Superior. Nesse sentido, cabe-nos destacar a multiplicidade de encontros, de discussões, leituras, diálogos e exercícios sistemáticos de escrita, incursões na escola e na sala de aula os quais vêm possibilitando ressignificar a docência como profissão. 


\section{O PIBID NO CONTEXTO DO CURSO DE PEDAGOGIA: UM PERCURSO COLABORATIVO}

O subprojeto PIBID Pedagogia, desde meados dos anos de 2011, na Universidade Federal da Fronteira Sul (UFFS), vem se apresentando para o Curso de Pedagogia,-como um esforço continuo de aproximação com os campos de atuação profissional, forjando novas e constantes relações com as unidades escolares em suas diversidades e singularidades, apontando rumos, apresentando desafios, forjando estudos e práticas sistemáticas, num cenário, cujos sujeitos: crianças, estudantes da graduação e professores supervisores têm sido constantemente chamados a mudar/alterar/qualificar os seus fazeres, ante o protagonismo que se apresenta, "desenhado"4 pelas múltiplas linguagens referenciadas na contemporaneidade.

Nessa perspectiva, o Programa de formação inicial em destaque tem possibilitado redimensionar o projeto pedagógico em suas múltiplas interfaces, estabelecendo novos e constantes exercícios de reflexão, diagnóstico e materialização, compreendendo-os, como “[...] parte de um plano [processo] que dá um juízo sobre a instituição em todos ou alguns aspectos do marco operativo, que é a descrição do ideal de ser, agir e se organizar da instituição." (GANDIN, 2000, p. 31). As perspectivas evidenciadas (re)desenham os processos formativos, possibilitando aos estudantes do curso, um percurso formativo a ser desenvolvido na e pela escola que se estrutura em torno de um currículo ou de uma proposta pedagógica pensada e realizada de forma a assegurar o desenvolvimento pleno de cada um dos educandos. Assim sendo, cabe às diferentes modalidades da Educação Básica premeditar suas ações com vistas à educação integral dos sujeitos.

\footnotetext{
4 A expressão "desenhado" tipifica um cenário com exigências múltiplas, as quais precisam ser explicitadas, sob olhar atento e vigilante das escolas, famílias, instituições mais próximas das crianças.
} 
Destaca-se, igualmente, que a concepção de percurso formativo advém de um processo constitutivo e constituinte da formação humana, por meio da educação integral. Processo esse, materializado nas e pelas especificidades da escola. Cuja prerrogativa de formação integral intenciona o desenvolvimento de todas as possibilidades/capacidades humanas objetivadas por intermédio do processo histórico.

O preposto anterior justifica a presença e a ideia de pesquisa em sala de aula, como estratégia formativa, como possibilidade de desenvolvimento e aprendizagem do discente em processo de formação inicial. De acordo com Vieira (2002, p. 24-25):

A proposta da pesquisa em sala de aula constitui uma possibilidade concreta de produção de saber capaz de envolver professores e alunos em empreendimento coletivos de investigação, com efeitos surpreendentes sobre o processo ensino-aprendizagem e sobre a dinâmica de seu cotidiano.

Em razão disso, a estratégia da pesquisa referenciada pelas diferentes incursões e problematizações na prática educativa subsidiada pelos referenciais teóricos inerentes ao "continuum" da formação inicial e continuada, corroboram com a defesa crítico-reflexiva das três dimensões formativas apresentadas por Nóvoa (1995) como necessidades profissionais, quais sejam: a dimensão individual, profissional e organizacional. Dimensões essas articuladas entre si: o individual não prescinde do profissional e o organizacional para constituir-se requer múltiplas referência(ações) articuladas com compromissos éticos que agreguem à comunidade à qual se vincula.

Nesse sentido, a escola assumida como um espaço, lugar de mediação privilegiada no e do processo formativo do ser humano, funda-se e justifica-se em seu desafio maior, a capacidade de provocação, de mobilização e de construção de atitudes investigativas. Em razão disso, pensar o, e no percurso formativo implica, 
em boa medida, ter como foco os sujeitos e a sua formação cidadã, referenciada por processos dinâmicos, permanentes e inconclusos. É razão disso, que a escola deve aproximar-se e fortalecer-se com a educação integral, de forma que os processos de formação e de ensino e de aprendizagem aconteçam na relação com a totalidade formativa do sujeito, possibilitando o desenvolvimento e a aprendizagem destes, nas diferentes dimensões.

Assumindo a escola como campo, espaço, lugar e território de formação e atuação profissional, assumimos também o compromisso de preservá-la de modo que não fique à mercê de prerrogativas que desrespeitam sua singularidade e seu fazer, enquanto instituição que preserva, constrói e reflete o repertório cultural da humanidade. Espaço privilegiado a todos, para muito além do seu caráter obrigatório. Nessa afirmativa, reiteramos a necessidade de acolhimento e valorização dos profissionais da educação, prioritariamente o zelo ético para com a sua formação e profissão.

Akele (2002) dá destaque especial à mediação como instauradora de uma relação diferenciada e apresenta-a como uma possibilidade de interação entre a situação imediata real e a percepção episódica da realidade, assegurando a interação real do individuo com a construção do processo de conhecimento. Enfatiza que o processo se dará no contexto do discurso e nas interações sociais em sala de aula, privilegiando a dialogia necessária. Assim sendo, a aprendizagem compartilhada é uma forma privilegiada de apreensão das relações impressas e expressas, ler e escrever, deixam de ser apenas ferramentas de acesso ao saber sistematizado, para se constituírem em exercícios de apropriação dos processos de elaboração mental, os quais asseguram relações, entre o sistema de ligações e as relações e significações mediadas pelo professor.

Nesse sentido, Zeichner (2013) reitera que deveríamos buscar em um sistema de responsabilização por meio da formação de professores, uma leitura profunda e precisa da qualidade da formação dos professores que os cursos referendam ao estado 
quando da certificação inicial bem como um sistema que contribui para o contínuo aperfeiçoamento dos cursos de formação. $\mathrm{O}$ autor defende ainda a criação de novos "espaços híbridos" na formação universitária de professores, por meio dos quais o conhecimento acadêmico, o da escola e o da comunidade se relacionam de maneira menos hierárquica e acidental, tendo em vista apoiar em continuum o aprendizado do professor. Destaca ainda que alcançar objetivos comuns requer que os profissionais cruzem as fronteiras institucionais, pessoais e profissionais, combinando os recursos necessários, normas e valores de seus respectivos ambientes dentro das novas soluções híbridas. Isso não significa aligeirar, suprimir e, muito menos, desrespeitar o estatuto ético, demandado para uma profissão tal como a docência!

Nesse sentido, o compromisso ético assumido com o desenvolvimento da escrita, emerge no Programa, como tarefa formativa, que possibilita aos estudantes em formação, na parceria com o professor universitário e o professor da Educação Básica um exercício de libertação das amarras de uma prática escolar que se serviu da escrita para copiar o que os outros produzem.

\section{a) A escrita e os registros no diário de bordo: da reflexão sobre a prática, para o anúncio de novas práticas}

De acordo com os compromissos formativos inerentes ao PIBID, ancoramos a demanda do registro e da reflexão teórico-prática subsidiada pelos diários de bordo, como instrumentos formativos, assumindo a aprendizagem compartilhada como uma forma privilegiada de apreensão das relações impressas e expressas. Para Da Ros (2002), o ler e escrever deixam de ser apenas ferramentas de acesso ao saber sistematizado, para se constituírem em exercícios de apropriação dos processos de elaboração mental, os quais asseguram relações, entre o sistema e as relações e significações mediadas pelo professor. 
Na mesma perspectiva, Souza (2002) destaca que na constituição de desejo de escrever comunicando o ler, comunicando-se consigo mesmo e com os outros, reside o desafio que perpassa essa contribuição, o qual ancora-se na necessidade de ativarmos a formação de leitores e escritores, formadores de opinião, protagonistas, comprometidos com as novas e urgentes demandas sociais, legitimadores de valores, redimensionados e ou construídos coletivamente. Embora, defendamos o respeitar a história, a trajetória e a herança cultural da qual somos e nos tornamos tributários, a escola, precisa contribuir para que o aluno se sinta sujeito desse processo, propiciando-lhes oportunidades para pensar, buscar soluções. Nesse recorte formativo reside a ênfase e os compromissos éticos do PIBID, apreender a docência a partir dos lugares onde ocorre e se efetiva o processo de formação desejável para a atualidade: na universidade e na escola.

Tendo em vista os compromissos anunciados, damos prioridade ao exercício sistemático da escrita registrando o ocorrido, refletindo teoricamente os fatos e acontecimentos, privilegiando o respeito ao saber do outro e as possibilidades que dele emanam. Nessa relação, obtivemos a parceria do Programa de Educação Tutorial Letras/Pedagogia, na realização de oficinas de escrita acadêmica, o que contribuiu substancialmente para a qualificação dos exercícios cotidianos, impactando na qualidade acadêmica dos estudantes.

\section{b) Influências profissionais e as práticas pedagógicas acompanhadas (assistidas)}

Nada, nem ninguém, se constitui no que é, sem ter parâmetros de hominização, humanização, postura profissional, referências de ser e de se fazer gente. Imersos em tecnologias digitais a Era cyber vem refazendo o formar, o ver, o pensar e o estar no mundo. No entanto, a justa medida de Platão emerge 
como necessidade, na constituição de princípios éticos! Na era das tecnologias digitais, precisamos mais do que nunca olhar nos olhos, dialogar, escrever, ter o dizer, recolocando os processos formativos, tanto para os estudantes dos diferentes níveis de ensino quanto para os seus professores bem como para os diferentes segmentos da sociedade civil.

Bianchetti (2002) em um de seus artigos, em obra por ele organizada, apresenta o, escrever uma das $\operatorname{armas}^{5}$ do professor, afirma que todos os homens são intelectuais. Contudo faz uma ressalva aos intelectuais públicos, focando o eclipse desses, em relação à sua pouca partição na e com a escrita. Evidencia que esse espaço precisa ser ocupado e que para isso é preciso ler. Apresenta a leitura, como pré-condição para o escrever. Outro aspecto apresentado pelo autor tem a ver com as práticas da leitura e da escrita, visto serem para ele, essas "ginásticas do intelecto". Às contribuições e às reflexões do autor acrescentamos algumas problematizações: o que os intelectuais têm efetivamente feito para que os professores iniciantes; ingressantes na alfabetização na Educação Básica, nos cursos de graduação, para que esses desenvolvam essa ginástica intelectual? Que alcance, seus estudos têm possibilitado? Essas problematizações nos aproximam da escola, contribuindo na identificação dos referenciais chancelados pelo PIBID.

A problematização em destaque faz um chamamento a todos os intelectuais envolvidos nos processos educativos, em atenção às novas e constantes exigências presentes nos percursos formativos, trajetórias marcadas pelas mudanças, desafios e interlocuções efetuadas nos diferentes contextos educacionais. Se atentarmos para os processos de alfabetização e de letramento, conceitualmente e politicamente referenciados, facilmente

\footnotetext{
${ }^{5}$ Arma, como ferramenta formativa, expondo e dispondo seus jeitos de ser e fazer, possibilitando reflexões.
} 
percebemos a superficialidade com que acontecem. E particularmente a hegemonia das práticas tradicionais, referenciadas pelas clássicas cartilhas e livros didáticos, em detrimento das práticas e referenciais culturais que tipificam as realidades vividas pelas crianças, cujos textos e contextos são altamente formadores. O que temos são práticas tradicionais de ensino de leitura e escrita, distantes da vida e da realidade dos sujeitos aprendentes. O que fazer pode estar no nosso alcance!

A tentativa de superação dessas e outras contradições são exercícios que decorrem de diagnósticos e de cartografias das salas de aula e suas peculiaridades, assumidas como campo de estudo, reflexão e proposição. A realidade da sala de aula, a atuação do professor, os recursos e materiais disponíveis, dentre outros. De posse dos dados evidenciados, vem a tomada de decisão: os compromissos éticos assumidos coletivamente. Reconhecida a diversidade; ações teórico metodológicas, coerentes com os diferentes jeitos de aprender, com os diferentes níveis de aprendizagem, atividades individuais, coletivas em pequenos grupos, concebemos perspectivas de ensinar as quais possam contribuir para acolher as crianças reais que temos em sala de aula. O processo educativo na sala de aula é responsabilidade coletiva, o professor, seja ela unidocente ou não, precisa ser acolhido, ajudado, sem ser apenas corresponsabilizado pelos sucessos e ou fracassos que por ventura ali ocorrem e ou possam vir a ocorrer.

O diálogo sucessivo e próximo com os professores supervisores como coformadores, em encontros sistemáticos, em encontros na sala de aula e na escola e em encontros na universidade, demanda aportes teórico-práticos por parte de todos os envolvidos na devolutiva das observações e dos estudos realizados para subsidiar as demandas efetuadas pelos docentes e pelos discentes. $\mathrm{O}$ argumento de que a escola e a sala de aula continuam iguais, trata-se de ledo engano! "A sala de aula mudou e muito!"6

\footnotetext{
${ }^{6}$ Fala de estudante pibidiano, ante a postura, a fala e as atitudes das crianças na sala de aula.
} 
O monitoramento do planejado e do executado tem se constituído num exercício semanal. A constatação da necessidade de replanejamento e que essa prática venha, pois, a contribuir com o processo de aprendizagem das crianças/estudantes dos Anos Iniciais. O não planejamento a não sistematização e reflexão do fazer docente tem impactado na disponibilidade, na participação e na colaboração dos estudantes em sala de aula.

A leitura dos diários de bordo tem subsidiado a compreensão do movimento e da relação teoria e prática na sala de aula, evidenciando a dinâmica dos processos educativos e os desafios diários na sala de aula nos Anos Iniciais do Ensino Fundamental.

\section{À GUISA DE CONCLUSÃO}

Ao nos ocuparmos com a iniciação à docência - escolas e universidade, particularmente, por meio dos cursos de licenciatura -, passamos a nos ocupar das especificidades de uma profissão que vem carecendo de incentivos, no que se refere à adesão e à permanência, diante da solidão que os professores reclamam. Dados os desafios circunstanciais que a cercam a profissão docente na contemporaneidade, como: a desvalorização social da profissão do professor, a perda da autoridade social, os percalços da carreira, as contradições/formativas nutridas pelo aligeiramento, pela privatização dentre outros desafios contemporâneos, são indicadores de que o compromisso público, nunca se fez tão necessário, tendo em vista a qualidade de ensino desejada, não apenas para fazer frente às estatísticas de aprendizagem.

Há de se destacar que são variados e consistentes os argumentos em favor de processos de iniciação à docência enquanto um componente imprescindível tanto da quanto para a formação inicial e continuada, tendo em vista a prática docente e os processos formativos demandados para o professor da Educação Básica. 
Dentre eles, destacamos o uso e a efetividade da tecnologia da escrita, como uma das máximas invenções da humanidade a qual nos permite dialogar com o escritor, no tempo e espaço de produção, aprendendo a escrever, o que, de acordo com Paulo Freire, são atos culturais, apresentados como elementos essenciais no processo de produção/construção do conhecimento.

Dentre as particularidades desse processo formativo, trazemos a ação colaborativa, o trabalho coletivo, a autonomia intelectual, a atitude investigativa como exercícios em construção junto aos interlocutores: professores universitários, professores supervisores e estudantes do curso envolvidos no projeto em estudo. E que, o PIBID, enquanto política de formação inicial para a docência, por meio de seus diferentes exercícios de aproximação com a carreira docente, vem possibilitando conhecer as particularidades e os meandros dessa profissão; as alegrias e as frustrações dos profissionais e sua carreira como docente, as possibilidades e as contradições que circunscrevem a profissão docente, na sala de aula, nos corredores da escola, na própria escola, na biblioteca, no laboratório, na rua, enfim onde a docência se materializa.

Merece destaque também a reflexão crítica, que decorre sobre e a partir das vivências de estudantes e professores da Educação Básica, o que muitas vezes põe em cheque os saberes acadêmicos produzidos como verdades no âmbito da academia, em decorrência do distanciamento escola/comunidade/universidade. Novos e diários desafios e possibilidades (re)definem as relações e as práticas docentes dadas às novas e diversas possibilidades de aprendizagem e, por extensão, de ensino identificado no âmbito do aprender e do ensinar para os diferentes sujeitos.

Outro aspecto que advêm desse Programa é a potencialização da relação universidade escola pelo movimento formativo: inicial e continuado, pela relação teoria e prática, pelos estudos sistemáticos entre supervisores, coordenadores e bolsistas de Iniciação à docência na universidade e na escola. Isso obviamente, 
não se trata de um processo tranquilo, há tensionamento(s), há embates, há acolhimentos, acordos e discordâncias, trata-se de processo de formação acadêmico-profissional.

Dentre os múltiplos desafios circunscritos para essa política pública no decorrer da sua existência, está a formação do professor tendo em vista a cidadania plena para os pequenos/grandes cidadãos, marcados pelas mudanças curriculares, pelos movimentos e lutas da sociedade civil organizada e suas instituições formadoras incentivando a formação docente, valorizando a profissão, melhorando a qualidade da formação inicial pela integração Educação Básica e Superior. Além da inserção do estudante nas escolas com participação em experiências metodológicas de caráter inovador, tendo o professor da básica como interlocutor tendo em vista a superação da dicotomia teoria/prática. Estamos a caminho, escrever e refletir é preciso e necessário!

\section{REFERÊNCIAS}

AKELE, Dercy. A escrita numa perspectiva textual e a concepção dialética da linguagem. In: BIANCHETTI, Lucidio (org.). Trama e texto: leitura crítica e leitura criativa. 2. ed. São Paulo: Summus, 2002. p. 129-142.

BIANCHETTI, Lucidio (org.). Trama e texto: leitura crítica e leitura criativa. 2. ed. São Paulo: Summus, 2002. p. 185-190.

DA ROS, Silvia Zanatta. O chamado fracasso escolar e a aprendizagem da língua escrita. In: BIANCHETTI, Lucidio (org.). Trama e texto: leitura crítica e leitura criativa. 2 ed. São Paulo: Summus, 2002. p. 143-164.

GANDIN, Danilo. A prática do planejamento participativo. 8. ed. Petrópolis: Vozes, 2000.

GARCÍA, Carlos Marcelo. Formação de professores: para uma mudança. Lisboa: Porto, 1999. 
FUNDAÇÃO CARLOS CHAGAS. GATTI, Bernardete Angelina et al. Um estudo avaliativo do Programa Institucional de Bolsa de Iniciação à Docência (PIBID). Pesquisadores Bernardete A. Gatti, Marli E. D. A. André, Nelson A. S. Gimenes e Laurizete Ferragut. São Paulo: FCC/SEP, 2014.

FREIRE, Paulo. Pedagogia da autonomia: saberes necessários à prática educativa. São Paulo: Paz e Terra, 2009.

NÓVOA, António (org.). Vidas de professores. Porto Alegre: Porto, 1995.

PIMENTA, Selma Garrido (org.). Saberes pedagógicos e atividade docente. São Paulo: Cortez, 2000.

SOUZA, Hulda Cyrelli de. Produção textual: ação solitária ou solidária. In: BIANCHETTI, Lucidio (org.). Trama e texto: leitura crítica e leitura criativa. 2. ed. São Paulo: Summus, 2002. p.165-176.

TARDIF, Maurice. Saberes profissionais dos professores e conhecimentos universitários: elementos para uma epistemologia da prática profissional dos professores e suas consequências em relação à formação para o magistério. Revista Brasileira de Educação (ANPED), n. 13, p. 5-24, jan./fev./mar./abr. 2000.

TARDIF, Maurice. Saberes docentes e formação profissional. Petrópolis: Vozes, 2004.

TEMÓTEO, Antônia Sueli da Silva Gomes; SILVA, Cláudia Alves da. O Pibid como política pública de formação docente: discutindo resultados exitosos. Cadernos Cenpec, São Paulo, v. 4, n. 2, p. 108-121, dez. 2014.

VIEIRA, Sofia Lerche. Formação em pesquisa: a alternativa de caminhar em grupo. In: CAVALCANTE, Maria Marina Dias; NUNES, João Batista Carvalho de (org.). Pesquisa em educação na UECE: um caminho em construção. Fortaleza: Demócrito Rocha, 2002. p. 17-32.

ZEICHNER, Kenneth M. Políticas de formação de professores nos Estados Unidos: como e por que elas afetam vários países no mundo. Tradução de Cristina Antunes. Belo Horizonte: Autêntica, 2013. 